\title{
How to sponsor ground-breaking research: a comparison of funding schemes
}

\author{
Thomas Heinze
}

\begin{abstract}
A key challenge for research management and science policy is support of scientific exploration of new research frontiers. This paper examines funding schemes that aim to encourage scientists to conduct unconventional and high-risk research. Schemes are analyzed across institutional dimensions, such as: target group and field, selection process and criteria, budget size, and funding duration. It argues that sponsorship programs for ground-breaking research should: respond to the existing talent pool rather than setting arbitrary funding thresholds, undertake efforts to contend with the selection bias of peer review, and take an applicant's ongoing research into account. It discusses whether such programs should be within existing funding organizations, or if new funding agencies that are dedicated to sponsoring ground-breaking research should be set up.
\end{abstract}

$\mathrm{S}$ cientists and science policy makers are paying greater attention to the importance of funding mechanisms for the proper conduct of research (Laudel, 2006; HLEG, 2005; Bourke and Butler, 1999). Today, how research money is packaged, earmarked, distributed and finally spent within and across research institutions influences the working conditions under which research is carried out in laboratories.

One major challenge for research management and science policy is to support scientists in their endeavors to search for novel and unconventional research venues, and thus to explore new research frontiers. Yet, because experimentation with new alternatives offers returns that are uncertain, distant,

Dr. Thomas Heinze, Fakultät für Sozial- und Wirtschaftswissenschaften, Universität Bamberg, Postfach 1549, 96045 Bamberg, Germany; Email: thomas.heinze@uni-bamberg.de.

This paper is based on research undertaken by the PROMISE project and the CREA project both sponsored by the European Union NEST program (available at <http://ec.europa.eu/ research/fp6/index_en.cfm?p=8_nest>, last accessed: 17 January 2008). The author is grateful for the asistance with the program survey, in particular from: Patrick Prendergast, Sheena Brown, Philip Shapira, Concettina Larosa, Tiziana Lombardo, Shula Bonjack, Andrzej Slawinski and Jakob Edler. The author is also grateful for help from Sandra Gröhl and the many comments and suggestions provided by Eli Pollak. and often negative, exploration of new research paths is often discouraged. In contrast, returns on the refinement and extension of existing competences, technologies, and paradigms are positive, proximate, and often predictable, thereby encouraging exploitation of existing research paths. The distance in time and space between the locus of learning and the locus for the realization of returns is generally greater in the case of exploration than in the case of exploitation (March, 1991).

During the past three decades, a major trend in the governance of public research institutions involves an increase in the share of external, peer-reviewed funding from research councils (Laudel, 2006; Langfeldt, 2001; Bourke and Butler, 1999). ${ }^{1}$ The result of this rising dependence on external project funding is that scientists are forced into a competitive environment driven by evaluation for the allocation of these scarce funds. The underlying rationale of this shift is that increased competition for funds will draw out the best ideas and encourage research collaboration (Shapira and Kuhlmann, 2003). The consequences of this trend, however, are ambivalent and contested. Because external funding is frequently linked to some form of peer review, the major challenge in distributing such funding streams arises from the tension between the plausibility and scientific value of the research on one hand, and its originality and creativity on the other. Whereas 
Thomas Heinze, is assistant professor at the Faculty of Social and Economic Sciences, University of Bamberg, Germany. He obtained a Diploma in Sociology and a Ph.D. in Administrative Sciences. Previously, he worked as postdoctoral researcher at the Department of Science, Technology, Health and Policy Studies, University of Twente, The Netherlands; and as a senior researcher at the Fraunhofer Institute for Systems and Innovation Research, Germany. Current research topics include: institutional conditions for research creativity, public and private research sector governance, inter-institutional collaboration dynamics, commercialization of high-technologies. His broader research interests include: organizational sociology, institutionalism, governance theory, and sociological theory.

evaluating proposals on criteria of plausibility and scientific value encourages conformity with current scientific practice, valuing originality and creativity encourages dissent, because although scientific originality springs from scientific tradition, it also supersedes it (Polanyi, 1969).

This tension is illustrated in the quantum theory of Nobel Prize winner Max Planck, about which Polanyi writes: 'Although many striking confirmations of [Planck's theory] followed within a few years, so strange was Planck's idea that it took eleven years for quantum theory to gain final acceptance by leading physicists' (Polanyi, 1966: 67). A more recent example is the path-breaking economic theory of asymmetric information and adverse selection of Nobel Prize winner George Akerlof, whose contribution was initially rejected by three major economics journals (Akerlof, 1994: 65). The Planck and Akerlof examples demonstrate that novel and thought-provoking contributions do not always resonate positively with contemporary scientific communities but are sometimes met with initial resistance and hostility. Scientific knowledge must be validated, and validation is a communal process. The scientific community must eventually be persuaded that the new idea is valid. Therefore, funding structures with a strong peer-review component tend to overfund mainstream research that follows established research lines, particularly in traditional disciplines. Although peer review is widely used for judging grant applications, it has been found to be risk averse and biased against speculative, unorthodox and multidisciplinary research proposals (Langfeldt, 2001; Berezin, 1998; Bourke and Butler, 1999; Horrobin, 1996; Travis and Collins, 1991; Chubin and Hackett, 1990).

The paper aims to identify aspects of funding structures that are pivotal in supporting the exploration of new alternatives rather than the exploitation of existing paths in science. Therefore, we identify and review a set of funding schemes that have the mission of allowing scientists and research groups to enter the exploration mode, to conduct unconventional and high-risk research, and to go beyond established disciplinary knowledge and research paths. The following key questions guide the program review:
- Which deficiencies in existing funding structures are addressed by programs for ground-breaking research?

- For how long and at which funding levels are scientists supported in such funding schemes?

- Which procedures and criteria are used to select scientists for such funding programs?

- What are the strengths and weaknesses of existing funding programs for ground-breaking research?

This paper is part of a larger international research project that aims at understanding the organizational and institutional conditions of creativity in science. The desire to know more about the factors that contribute to research creativity has given impetus by the substantial changes seen over the last three decades in the institutional and organizational conditions under which scientific research is conducted. In an earlier paper, Heinze et al. (2007a) addressed research creativity by developing a functional typology of five major categories of creative research accomplishments. Furthermore, we examined the impact of funding and other organizational factors on the capability of scientists and groups to undertake original and ground-breaking research (Heinze et al., 2007b, 2008).

This paper compares existing funding programs, anchored in diverse research systems such as the UK, the USA, Germany, and Israel, which all aim to support ground-breaking work in science. We regard this comparison as a first step in identifying the operational aspects of such programs that increase the likelihood of supporting high-risk and outside-thebox research. We base our program comparison on criteria and dimensions (partly) derived from the existing literature on funding structures and their influence on research quality and impact. Then, based on our ongoing research project which examines institutional conditions of highly creative research accomplishments, we focus on nine funding initiatives. We apply our criteria for comparison to the analysis of documents, such as program brochures or websites, and also to a postal survey to retrieve basic program data from funding organizations and for qualitative interviews with representatives of funding agencies and recipients of such funding. The concluding section provides a summary of the findings from the literature review and program comparison, and a discussion of the policy conclusions.

\section{LITERATURE REVIEW}

The variety of existing mechanisms for funding scientific research is considerable. These mechanisms range from personal grants, faculty positions or science awards endowed with research money at the individual level, to core funding, temporary research center funds or multidisciplinary consortia funding at the organizational level, to key technologies 
schemes or priority initiatives at the program level. In addition to sponsoring the university system, several countries are also committed to funding extra-university public research institutions which themselves have developed different sets of funding modes and mechanisms (Jansen, 2007; Laredo and Mustar, 2001; Crow and Bozeman, 1998). Despite this variety of funding mechanisms, however, our current understanding of how these procedures influence knowledge production, and how they subsequently affect scientists' research strategies, is sparse. Comparative studies that investigate the impacts of internal, external, competitive, block grant or institutional funding, as well as combinations of these, on the conduct of scientific research and on research quality are conspicuously lacking. Consequently, little systematic knowledge exists from which to answer the question of how groundbreaking research can be effectively organized and funded. In the following, we discuss findings from studies which address the relationship between funding mechanisms and their impact on research content, scientific quality and productivity. From this literature, we derive criteria for the program comparison later in this paper.

Bourke and Butler (1999) compare the impact of short-term versus long-term funding in the biological sciences in Australia. They examine the degree to which multiple-year grant holders from the Australian Research Council (ARC) differ in their publication output and citation impact from scientists with long-term employment contracts in institutions with stable funding, such as medical research institutes (MRI), hospitals or ARC research centers. In addition, the authors differentiate within the group of grant holders between those who receive three-year grants while retaining their teaching function, and those who are employed as full-time research fellows for three to five years, respectively. Their findings suggest that research funded by such institutions with stable funding, such as the ARC research centers and MRI, have a much higher impact compared to ARC grant holders. Even within the latter category, those with contracts for up to five years are more productive and more often cited than those with only three-year grants.

The authors conclude that the time regime underlying institutional funding 'may allow for the identification of research problems of wider and deeper content, closer to the "state of the art" work in the field'. In contrast, short-term funded grants 'may predispose researchers to choose lesser problems capable of more predictable and safe completion' (Bourke and Butler, 1999: 499). In other words, short-term funding tends to encourage the exploitation mode which favours risk-averse research strategies and leads to proximate and often predictable outcomes, while high-impact research seems to be connected to the explorative mode conducted using long-term funding.

\section{Short-term funding tends to encourage the exploitation mode which favours risk-averse research strategies and leads to proximate and often predictable outcomes, while high-impact research seems to be connected to the explorative mode conducted using long-term funding}

In her study of how Australian and German physicists adapt the content of their work to existing funding conditions, Laudel (2006) reports that in research systems with little, no or decreasing core organizational funding, scientists are ever more dependent on sponsorship from external agencies and thus upon their governance in the selection and distribution of funds. Among the various strategies they use to cope with this situation, scientists tend to accept externally predetermined topics or themes, avoid risky research and try to work in niche areas (Laudel, 2006: 496-497). Competitively funded projects, according to the author, 'promote low-risk, mainstream, "cheap", applied, inflexible research. Scientists' adaptations to the institutional conditions of funding (...) have widespread side effects that, in the perception of scientists, restrain the quality and innovativeness of their research' (Laudel, 2006: 502).

Despite the commonly held assumption that these negative side effects pertain only to mediocre scientists, Laudel finds that all scientists, including top scientists (defined as the upper third of the citation distribution), are negatively affected by these funding conditions. Even in top departments, the low level of core funding makes it impossible for institutions to fully fund renewal and maintenance costs for research instrumentation and personnel. Most importantly, Laudel argues that, external project funds are necessary today to conduct research at all, a function that was previously assumed by core organizational funding. In a system with high core institutional funding, external sponsorship enables research that departs from the main path. But in a system without such core funding, scientists are critically dependent on external money in order to conduct any research. Thus, Laudel finds that longterm research questions tend to be discontinued, because such questions typically produce results in a time frame far longer than those realized by two- or three-year projects (Laudel, 2006: 494-496). In other words, the forces of exploitation are strengthened by funding structures that systematically discourage 'spontaneous, "playful” research, changes of research trails, and the search for new connections between fields'. Consequently, the exploration of 
new alternatives and paradigms might become 'endangered species' in science (Laudel, 2006: 503).

Another study examines the effects of a prestigious funding scheme of the Swedish Foundation for Strategic Research for highly talented junior scientists (Melin and Danell, 2006). The authors report that 40 candidates were invited from a pool of 500 applicants, a homogenous group of scientists among whom there were no significant differences in terms of their research productivity and quality. Because the scheme provided funding for only 20 scientists, half of the talent pool ended up without funding. The authors' interviews suggest, however, that because of the restricted funding situation, chance and subjectivity entered the final selection round. Some candidates were approved 'because their performance at the interview or because the design of the project happened to seem more interesting to the final evaluators, or because of other intuitive reasons rather than quality-related ones'. With different people on the panel or a different interviewing order, 'the outcome could very well have been different' (Melin and Danell, 2006: 710).

Melin and Danell also investigate the impact of the funding decision upon the subsequent productivity and quality of research development of all 40 candidates. In responses to the authors' questionnaires, many of the 20 scientists who were not funded in the final round replied that they were unable to pursue the research questions they would have liked to pursue, that they were forced constantly to hunt for new funds thereby losing a considerable share of their working time, and that they could not engage in risky projects. Although most of these 20 scientists were able to access other funding channels, they reported that in light of constraints imposed by external funding agencies these projects could not be developed with proper focus and direction (Melin and Danell, 2006: 709-710).

Melin and Danell find that four years after the funding decision, both funded and non-funded candidates performed similarly in terms of productivity and research quality. However, while the funded group of 20 scientists showed a much more homogenous performance profile, the performance heterogeneity of the group of non-funded scientists had grown substantially. The successful candidates were able to enhance and strengthen their research profile. This process was more difficult and less certain for the non-successful candidates (Melin and Danell, 2006: 705-706). The authors conclude that 'the cost of not having provided the 20 rejected applicants in this study probably exceeds the cost of 20 additional (...) grants substantially'. Therefore, good practice in research policy 'would locate the point of breakeven in any application round, where the quality of the applications and the potential of the applicants are good enough for a grant to be beneficial' (Melin and Danell, 2006: 712).

Another recent study examines organizational and institutional factors that allow scientists and groups to undertake original and path-breaking research (Heinze et al., 2007b, 2008). Flexible research funds are identified as a key factor in this regard. These funds include: organizational core funding, funds from agencies with a mission to fund nonmainstream research and large multi-year awards with few budget restrictions regarding the use of personnel, equipment, consumables or operating costs. The authors point out that funding is typically linked to other institutional factors. These factors include the freedom to define and pursue individual scientific interests, facilitative group leadership, small group size, an organizational context that includes a complementary variety of scientific skills and instrumentation, organizational arrangements that support unplanned multidisciplinary contact, the presence of a guiding research vision and scientific reputation. These factors together make up an environment conducive to creative research (Heinze et al., 2008).

The authors also find that the manner in which the responsibility for a certain field of research is allocated to a particular division of a funding agency and advised by experts in the area often becomes a significant barrier to creative research because each division tends to award funds to scientists who have a record of publications in that specific area. Several of the research breakthroughs studied by Heinze et al., (2007b, 2008) were achieved by researchers who moved to a new field or who integrated new fields with their area of expertise. However, scientists need preliminary results in order to compete for external funds. Moving into a new field without obtaining these preliminary results is regarded as basically impossible. Current funding mechanisms, it seems, are not flexible enough to accept that scientists with excellent track records in their existing fields are capable of investigating phenomena that involve moving into new fields and that there are synergies in funding such research. Again, the forces of exploration are weakened by such funding mechanisms, because scientists are discouraged from entering new fields.

In conclusion, evidence in the literature suggests that:

\section{Current funding mechanisms, it seems, are not flexible enough to accept that scientists with excellent track records in their existing fields are capable of investigating phenomena that involve moving into new fields and that there are synergies in funding such research}


- Long-term funding mechanisms tend to support the exploration mode, which yields higher outcomes and greater impacts than short-term sponsorship of research

- External, peer-reviewed grant funding alone is insufficient if scientists are expected to conduct multidisciplinary research and thereby contribute to the advancement of science

- The scope and level of external funding programs should correspond to the actual pool of candidates at a given time, rather than imposing an arbitrary threshold on a given population of applicants

- Flexible research funding is best suited for the support of research groups who are conducting original, ground-breaking research

- A broad variety of funding mechanisms is better suited to enabling original research than reliance on only one funding mechanism

In recent years, several public and private agencies have established dedicated programs with the aim of enabling and supporting unconventional, outside-thebox research. This development can be interpreted, at least partially, as a response to the widespread criticism that many agencies are inclined to support status quo projects rather than ground-breaking science.

Before comparing such programs, one should consider the criteria that the literature review offers for cross-comparisons. Although the analysis of the schemes needs to take into account their origins in national research environments (see section on identification of funding schemes), the following criteria are relevant to all programs:

- Funding duration: short-term versus long-term (Bourke and Butler, 1999; Laudel, 2006)

- Funding type: grants for individuals, project funding, institutional support (Bourke and Butler, 1999)

- Target group: elite researchers versus 'normal scientists' (Laudel, 2006; Melin and Danell, 2006)

- Target research field: single-field versus multiple fields (Bourke and Butler, 1999; Laudel, 2006; Heinze et al., 2008)

- Selection criteria: originality, riskiness, track record (Melin and Danell, 2006; Heinze et al., 2007b, 2008)

Additional criteria should complement these criteria. For instance, it would be useful to know the total budget available in order to estimate program size relative to more conventional funding channels. Similarly, program sponsors might be research councils with public money versus foundations distributing private money. Also, while in some cases established funding agencies with many funding streams, such as research councils or large private trusts, might administer funding schemes, in other cases they might be the exclusive sponsorship channel of their host organization. Hence, the program comparison draws upon a wider set of criteria than those derived from the literature review (see section on scheme comparison later in this paper).

\section{IDENTIFICATION OF FUNDING SCHEMES}

\section{Study on institutional conditions of research creativity}

The identification of programs for ground-breaking research draws upon two main sources. First, in the context of an international research project on organizational and institutional conditions of creativity in science (Heinze et al., 2007b), we connected four research breakthroughs to the following funding schemes: 21st Century Science Initiative (James S. McDonnell Foundation, USA), Investigator Program (Howard Hughes Medical Institute, USA), European Young Investigator Award (European Science Foundation), and Förderpreis für junge Hochschullehrer (Alfried Krupp von Bohlen und Halbach Foundation, Germany). Although these four programs did not directly sponsor the respective research breakthroughs, there were hints that they helped the creative accomplishment materialize. In addition, the European Research Council (ERC) Starting Independent Researcher Grant Scheme, launched in 2007, entered the sample as the successor to the European Young Investigator Award (European Science Foundation). Below are brief descriptions of the five schemes.

\section{Howard Hughes Medical Institute: Investigator Program (HIP)}

The Investigator Program of the Howard Hughes Medical Institute (USA) seeks out highly creative investigators at distinguished universities, research institutes, and medical schools across the USA whose work spans the full range of leading-edge biological and biomedical research. Specifically, the program solicits talented and productive scientists who identify and rigorously pursue significant questions in biology, push their chosen field into new areas of inquiry, develop new tools and methods that enable creative experimental approaches, and forge links between basic biology and medicine. Funding is generally very flexible, requiring no annual reports or renewal applications.

\section{Alfried Krupp von Bohlen und Halbach Foundation: Junior University Professor Program (KFP)}

The Krupp Award for Junior University Professors (Förderpreis für junge Hochschullehrer) of the Alfried Krupp von Bohlen und Halbach Foundation (Germany) was instituted to encourage outstanding and highly talented junior faculty members in science and engineering to pursue their research agendas by 
providing them with additional equipment and staff. The scheme assumes that junior faculty need additional resources in order to pursue their research most effectively. It covers expenses up to the level of a full professorial chair. Candidates should not be over 38 years old, and their applications are submitted by their home institutions.

\section{James S. McDonnell Foundation:} 21st Century Science Initiative (MSI)

The 21st Century Science Initiative of the James McDonnell Foundation (USA) was created to invest in the acquisition of new knowledge and in the responsible application of knowledge for solving realworld problems. Projects should be submitted at an early, even preliminary, stage of development and aim to break new ground or to challenge commonly held assumptions. Applications should be sufficiently novel, cross-disciplinary, or heterodox as to render them unlikely candidates for funding from other agencies.

\section{European Science Foundation: European Young Investigator Award (EUYRI)}

The European Young Investigator Award was operated in the period from 2003 to 2007 by the European Science Foundation. It aimed to attract outstanding young scientists from all over the world to work in Europe to establish their first research groups, and to build up the next generation of leading European researchers. The scheme supported proposals designed to open up new lines of research including novel methodologies. Candidates were expected to have received a Ph.D. from two to eight years prior to submitting their applications. Following the establishment of the new grant schemes of the European Research Council (see below), the European Young Investigator Award was discontinued in 2007.

\section{European Research Council: Starting Independent Researcher Grant (IRG)}

The ERC Starting Grant by the European Research Council (EU) is designed to support researchers who are starting their first research teams or, depending on the field, are establishing their independent research programs. The main function of the scheme is to provide support for the establishment of independent and excellent new individual research teams. The grants are very flexible, including rebudgeting by the investigator and allowing the purchase of necessary equipment even at later stages of the award period. Most importantly, the grant is awarded to the investigator and is therefore portable between host institutions within the EU member states and other associated countries. Applicants should be less than 10 years away from the award of a Ph.D.

\section{International survey of high-risk funding schemes}

Our second source for identifying funding schemes was a combined postal and email survey conducted in 2006. The questionnaire included the criteria identified earlier in this paper, but also involved other descriptive aspects and dimensions (see Appendix 1). The recipients were public research councils and private research foundations but also national research ministries and academic societies in Europe and the USA targeting program proposals that support 'novel, ambitious, unconventional, and high-risk research'. In total, we received 71 responses (ca. $22 \%$ response rate); of these, 40 were from agencies that reported operating schemes dedicated to ground-breaking research. ${ }^{2}$ Although several of these self-assessments overstated the extent to which funding schemes address high-risk research, they provided valuable initial data. On the basis of access to additional information, such as brochures, websites, and contact persons, we selected four schemes for in-depth analysis: Showcase Award (Wellcome Trust, UK), IDEAS Factory (Engineering and Physical Science Research Council, UK), Off the Beaten Track (Volkswagen Foundation, Germany), and Focal Initiatives in Research in Science and Technology (Israel Science Foundation, Israel). ${ }^{3}$

\section{Wellcome Trust: Commemorative Award for Innovative Research (WCA)}

The Sir Henry Wellcome Commemorative Award for Innovative Research, also referred to as the 'Showcase Award', was operated between 1996 and 2003 by the Wellcome Trust (UK) in support of research that was innovative, speculative, adventurous and novel, and beyond the trust's normal funding pattern. The scheme was developed to support scientists investigating pioneering and speculative research concepts, with a decision-making protocol designed to eliminate the barriers that prevent such projects from being supported via other funding streams. Although no formal requirement as to age or experience applied, the majority of awardees had at least ten years post-doctoral research experience, and were established university researchers with lectureships or senior fellowships.

\section{Engineering and Physical Sciences Research Council: IDEAS Factory (IDF)}

The Ideas Factory Program of the Engineering and Physical Science Research Council (UK) is dedicated to finding a new way to generate research projects coupled with real-time peer review. It aims to stimulate highly innovative and riskier research activities that would be difficult to conceive under traditional circumstances. Funding is allocated through realtime peer review, a residential interactive workshop 
over five days involving 20-30 participants, the director and a number of independent stakeholders. The aim of the scheme is not to spread the funding evenly across the participants of the real-time peerreview event. It may be that no new ideas arise, or that only one or two projects are successful. Numerous outcomes are possible, ranging from a single large research project to several smaller projects, feasibility studies, networking activities or overseas visits.

\section{Israel Science Foundation: Focal Initiatives in Research in Science and Technology (FIRST)}

The Focal Research Initiatives in Science and Technology by the Isreal Science Foundation (Israel) are intended to support areas of basic research that are insufficiently developed and yet of strategic importance to Israeli research, as well as to support novel and risky projects, preferably with interdisciplinary content, which are hard to evaluate through traditional peer-review mechanisms. It supports research that is either inter- or intradisciplinary, which therefore cannot obtain support through regular funding channels, or high-risk research for which preliminary data is not yet available. With respect to the latter, the scheme supports preliminary research so that in the future scientists will be able to apply for regular funding streams.

\section{Volkswagen Foundation: Off the Beaten Track (VOBT)}

The VOBT (Germany) program aims to identify and fund projects that would have difficulties within traditional funding schemes because of their interdisciplinarity, the high risk involved, or their unconventional approaches. It aims at research projects that pursue innovative and unusual lines of research and are not in the mainstream of their respective fields. Those who wish to obtain support must not only satisfy the highest scientific standards but must also plausibly demonstrate that no support can be obtained from among the regular funding offers of other institutions or from other programs of the Volkswagen Foundation.

\section{SCHEME COMPARISON}

We base our comparison of funding schemes on several data sources, most importantly the questionnaire data (see Appendix 1), annual reports (e.g. Howard Hughes Medical Institute 2004, 2005; Krupp-Stiftung 2004), websites (see Notes at the end of this paper), and qualitative expert interviews (see Appendix 2). In addition, evaluation reports are available for two programs: the Showcase Award Scheme of the British Wellcome Trust (Grant and Allen, 1999) and the European Young Investigator Award of the European Science Foundation
(Langfeldt and Brofoss, 2005). While these data sources allow us to draw conclusions with respect to the four questions we introduced in an earlier section of this paper, we do not evaluate the effectiveness of the schemes. We do not ask whether these funding schemes have, in fact, led to research breakthroughs. Although there are hints that the four schemes introduced in the previous section are related to groundbreaking research, a systematic evaluation of all schemes would require a different methodology. Hence, the comparison is a first step towards identifying the structural and operational aspects of funding schemes that tend to support high-risk and outside-the-box research.

Table 1 provides a first descriptive overview. Private, nonprofit organizations fund five of the initiatives, including four foundations and one biomedical research organization. Research council agencies sponsor the other four schemes, primarily from public funds. The majority of the schemes were implemented after 2000; only two programs (HIP and KFP) are over 20 years old. Two programs were terminated after several years (WCA and EURYI). Some programs are open to all research fields (EURYI, VOBT, FIRST, IRG); others only fund particular fields, such as the biomedical sciences (HIP and WCA) or science and engineering (KFP). Some only allocate funds for specific topics (MSI and IDF). Only two schemes are open either to the international research community (MSI) or the European scientific community (EURYI and IRG), while the majority of the programs address national research communities. To organize the program comparison systematically, the following paragraphs refer to the four research questions stated in the introduction of this paper.

\section{Which deficiencies in existing funding structures are addressed by programs for ground-breaking research?}

The fact that most programs are embedded in their respective national research systems reflects efforts to remedy specific deficiencies in these systems with regard to the exploration mode in science. In this respect, the HIP is an interesting example. At least two aspects of HIP contrast with the typical funding structures in the USA which, as one might argue, potentially counteract the exploration mode. First, most university professors do not have access to core institutional funding for research. Rather, they depend on grants from various funding agencies to do research at all. In contrast, HIP provides such core institutional funding including resources for infrastructure, instrumentation, and administration (Hughes Medical Institute, 2004, 2005). Second, while the majority of research money in the USA is distributed via two- and three-year projects, as is common for the National Science Foundation or other funding agencies, HIP emphasizes supporting 'people, not projects' in the long term. ${ }^{4}$ Over a time 
Table 1. Overview on funding schemes for highly creative research

\begin{tabular}{|c|c|c|c|c|c|c|c|c|c|}
\hline & $\begin{array}{l}\text { Hughes } \\
\text { Investigator } \\
\text { Program } \\
\text { (HIP) }\end{array}$ & $\begin{array}{c}\text { Krupp } \\
\text { Förderpreis } \\
\text { (KFP) }\end{array}$ & $\begin{array}{c}\text { Wellcome } \\
\text { s Commemorativ } \\
\text { Award (WCA) }\end{array}$ & $\begin{array}{c}\text { McDonnell } \\
\text { e } 21^{\text {st }} \text { Century } \\
\text { Science } \\
\text { Initiative } \\
\text { (MSI) }\end{array}$ & $\begin{array}{l}\text { Volkswagen } \\
\text { Off the } \\
\text { Beaten } \\
\text { Track } \\
\text { Scheme } \\
\text { (VOBT) }\end{array}$ & $\begin{array}{l}\text { Focal } \\
\text { Initiatives in } \\
\text { Research in } \\
\text { Science \& } \\
\text { Technology } \\
\text { (FIRST) }\end{array}$ & $\begin{array}{l}\text { European } \\
\text { Young } \\
\text { Investigator } \\
\text { Award } \\
\text { (EURYI) }\end{array}$ & $\begin{array}{l}\text { Ideas } \\
\text { Factory } \\
\text { (IDF) }\end{array}$ & $\begin{array}{c}\text { ERC } \\
\text { Independent } \\
\text { Researcher } \\
\text { Grant (IRG) }\end{array}$ \\
\hline $\begin{array}{l}\text { Funding } \\
\text { organization }\end{array}$ & $\begin{array}{l}\text { Howard } \\
\text { Hughes } \\
\text { Medical } \\
\text { Institute }\end{array}$ & $\begin{array}{l}\text { Krupp von } \\
\text { Bohlen und } \\
\text { Halbach } \\
\text { Stiftung }\end{array}$ & Wellcome Trust & $\begin{array}{l}\text { James S. } \\
\text { McDonnell } \\
\text { Foundation }\end{array}$ & $\begin{array}{l}\text { Volkswagen } \\
\text { Foundation }\end{array}$ & $\begin{array}{l}\text { Israel } \\
\text { Science } \\
\text { Foundation }\end{array}$ & $\begin{array}{l}\text { European } \\
\text { Science } \\
\text { Foundation }\end{array}$ & $\begin{array}{l}\text { Eng. \& } \\
\text { Phys. } \\
\text { Sciences } \\
\text { Research } \\
\text { Council }\end{array}$ & $\begin{array}{l}\text { European } \\
\text { Research } \\
\text { Council }\end{array}$ \\
\hline Country & USA & Germany & UK & USA & Germany & Israel & $\begin{array}{l}\text { EU member } \\
\text { states }\end{array}$ & UK & $\begin{array}{l}\text { EU member } \\
\text { states }\end{array}$ \\
\hline Start year & 1985 & 1986 & 1996 & 2000 & 2001 & 2002 & 2003 & 2005 & 2007 \\
\hline End year & Ongoing & Ongoing & 2003 & Ongoing & Ongoing & Ongoing & 2007 & Ongoing & Ongoing \\
\hline $\begin{array}{l}\text { Target } \\
\text { research } \\
\text { areas }\end{array}$ & $\begin{array}{l}\text { Biomedical } \\
\text { sciences }\end{array}$ & $\begin{array}{l}\text { Science and } \\
\text { engineering }\end{array}$ & $\begin{array}{l}\text { Biomedical } \\
\text { sciences }\end{array}$ & $\begin{array}{l}\text { Bridging } \\
\text { brain, mind, } \\
\text { behaviour; } \\
\text { complex } \\
\text { systems; } \\
\text { brain cancer }\end{array}$ & $\begin{array}{l}\text { All research } \\
\text { fields }\end{array}$ & $\begin{array}{l}\text { All research } \\
\text { fields }\end{array}$ & $\begin{array}{l}\text { All research } \\
\text { fields }\end{array}$ & $\begin{array}{l}\text { Topics that } \\
\text { need new } \\
\text { dimension } \\
\text { of thinking }\end{array}$ & $\begin{array}{l}\text { All research } \\
\text { fields }\end{array}$ \\
\hline $\begin{array}{l}\text { Program } \\
\text { scope }\end{array}$ & National & National & National & International & National $^{1}$ & National & International $^{2}$ & National & |nternational $\left.\right|^{2}$ \\
\hline $\begin{array}{l}\text { Target } \\
\text { groups }\end{array}$ & $\begin{array}{l}\text { Top faculty } \\
\text { (tenured) }\end{array}$ & $\begin{array}{l}\text { Top junior } \\
\text { faculty } \\
\text { (tenured) }\end{array}$ & $\begin{array}{l}\text { Any } \\
\text { researcher }\end{array}$ & $\begin{array}{l}\text { Top junior } \\
\text { faculty } \\
\text { (tenured) }\end{array}$ & $\begin{array}{l}\text { Any } \\
\text { researcher }\end{array}$ & $\begin{array}{l}\text { University } \\
\text { researcher }\end{array}$ & $\begin{array}{l}\text { Top junior } \\
\text { scientists } \\
\text { (tenured or } \\
\text { non-tenured) }\end{array}$ & $\begin{array}{l}\text { Any } \\
\text { researcher }\end{array}$ & $\begin{array}{l}\text { Top junior } \\
\text { scientists } \\
\text { (tenured or } \\
\text { non-tenured) }\end{array}$ \\
\hline $\begin{array}{l}\text { Funding } \\
\text { type }\end{array}$ & $\begin{array}{l}\text { Individual } \\
\text { grant }\end{array}$ & $\begin{array}{l}\text { Individual } \\
\text { grant }\end{array}$ & Project funding & $\begin{array}{l}\text { Individual } \\
\text { grant }\end{array}$ & $\begin{array}{l}\text { Project } \\
\text { funding }\end{array}$ & $\begin{array}{l}\text { Project or } \\
\text { institutional } \\
\text { funding }\end{array}$ & $\begin{array}{l}\text { Individual } \\
\text { grant }\end{array}$ & $\begin{array}{l}\text { Project } \\
\text { funding }\end{array}$ & $\begin{array}{l}\text { Individual } \\
\text { grant }\end{array}$ \\
\hline
\end{tabular}

Notes: 1. If international applicant, German research partner required

2. Only citizens of EU member states

span of at least five years, HIP investigators have full freedom with respect to organizing their research groups and setting research targets. Together, core institutional funding and the long-term perspective in research sponsorship contrast with the dominant funding model in the United States. Our interviewee from the Howard Hughes Medical Institute and one current HIP investigator both emphasized HIP's commitment to the exploration mode (Interviews 4 and 8). The former argued that 'even if something is discovered that bears no relationship to what the [investigators] talked about five years ago, if they have made an important breakthrough scientifically, we are delighted. And so they are free to go wherever the opportunity presents itself' (Interview 8).

Another example is the Krupp Award for junior university professors. This scheme was specifically set up to improve the equipment level of highly talented junior faculty members to facilitate pursuit of their research agenda. Assuming that junior professors in German universities have access to core institutional funds below the levels required to compete successfully with more established professors in Germany and in the international scientific community, the scheme covers expenses up to the level of a full professorial chair. The sponsorship support for junior professors does not come close to matching that of the higher-grade professors, who often exercise control over the entire budget of a university institute; thus, the Krupp Award amends this traditional, seniority-based support hierarchy in the German research system. Two recipients of the Krupp Award have stated that this scheme considerably upgraded their research base (Interviews 1 and 2).

Apart from attempts to remedy the exploitation mode biases specific to national research systems, all nine programs strive to counterbalance the more general forces of exploitation, such as withindiscipline reward mechanisms or the bias of peer review against speculative, unorthodox, and multidisciplinary research proposals. The programs go 
about strengthening the exploration mode in different ways, however, and two basic types of approach emerge. The first approach typically targets high-potential scientists and provides them with individual grants. Programs, such as HIP, KFP, MSI, EURYI, and IRG fall into this category. The second approach targets high-risk research projects open to any researcher in public institutions, typically university researchers. Programs such as: WCA, VOBT, IDF, and FIRST fall into this category.

The funding philosophy of programs in the first category is perhaps most explicitly stated in the description of HIP, but it is also evident in MSI. HIP rests on the conviction 'that scientists of exceptional talent and imagination will make fundamental contributions of lasting scientific value and benefit to mankind when given the resources, time, and freedom to pursue challenging questions'.5 Similarly, MSI requests that applications 'should be at an early, even preliminary stage of development that intend to break new ground or to challenge commonly held assumptions'. Proposal ideas are expected to 'be sufficiently novel, cross-disciplinary, or heterodox that they would not be strong candidates for federal funding'. 6 In contrast to more traditional funding schemes, MSI does not require applicants to outline every step in their research proposal. Rather, MSI encourages work that explores new research territory with novel questions that address underlying assumptions about ongoing research in the field. Consequently, the target group of the MSI program is scientists who attempt to do something that is 'not totally in the mainstream' and who 'bring a certain strength or different perspective' to their home institution that will 'influence the way students are trained or the way their colleagues think about their research’ (Interview 7).

The funding philosophy of programs in the second category is different. Although these programs also aim to support ambitious and multidisciplinary research, they want to attract and fund projects rather than people. In addition, they are based on the premise that there are ideas outside existing thematic programs of funding agencies that deserve support. For example, the idea of WCA was 'that the normal funding mechanisms were too conservative for some very interesting ideas, for example a scientist did not have a track record or there was very little published literature in the area, so there was very little proof that this would work as an idea' (Interview 3). WCA would sponsor this particular idea as a short-term project and provide scientists with extra support, such as one post-doctoral researcher for one year. At the time when WCA became operational, the assumption was that applicants had basic infrastructure and salary at their home institutions but needed extra time and money to try out new ideas. Similarly, VOBT addresses topics and themes that would not qualify for funding in research council programs, either because they are too interdisciplinary or too unusual. The Volkswagen Foundation set up this program to create 'a niche for unusual projects aside existing [project] funding streams' (Interview 6). Such niches were regarded as necessary in areas where too few proposals prevent funding agencies from launching thematic programs, and for topics with little chance of receiving support from research councils.

An example of multidisciplinary research under FIRST, a program in the second category, is a project that advanced archeological research by applying research techniques from physics. The FIRST program supported an exploratory project in which a physicist and two archeologists worked together to examine potsherds and stone tools using a state-ofthe-art three-dimensional scanning camera supported by advanced mathematical methods and computer algorithms. One major problem in examining potsherds and stone tools is the great number of artifacts scientists excavate at archeological sites. Although these artifacts provide the bulk of information, their very abundance actually hinders their detailed analysis. With traditional study methods, the sheer volume of evidence cannot be managed in a reasonable time and at a reasonable cost. In contrast, the project used the scanner for recording the shapes, textures, colors, and decorations of objects with high precision and efficiency, allowing the digital information to conveniently be stored, disseminated, and made available for further evaluation. The high quality of the images and their essentially unlimited quantity facilitated development of a refined, computerized typology and computerized comparative studies. ${ }^{7}$

To sum up, programs in the first category target individual scientists and provide them with the means to engage in the long-term development of sometimes risky ideas that might be too multidisciplinary or too unorthodox for research councils. Clearly, their focus is on the selection and the support of highly talented individual scientists. The traditional Harnack principle of the Max Planck Society in Germany states that institutes should be built around distinguished scientists; similarly, these programs rest on the conviction that outstanding individuals are the key drivers in the advancement of science. ${ }^{8}$ In contrast, programs in the second category target unconventional ideas that would likely be eliminated under peer review but that can be packaged into the format of a research project. As we describe below, the time frame of projects in the second program category rarely exceeds three years, and their budgets provide only limited additional funds to scientists and their groups. Such programs are perhaps best viewed as support vehicles for unconventional ideas that are developed until they are better suited for more traditional follow-up funding elsewhere.

It should be noted that the two program categories show considerable within-category variation. For instance, in the first group, differences exist in terms of the career stages of the target groups. HIP has traditionally tended to channel support to well- 
established scientists with extraordinary promise, but both MSI and KFP are dedicated to supporting and encouraging exceptional scientists and scholars in the earlier stages of their careers. EURYI and IRG target talented scientists at an even younger age. These two programs enable junior scientists to establish their first independent research groups. Below we discuss further variations between the two program classes, in particular with respect to the second and third research questions.

\section{For how long and at which funding levels are scientists supported in funding schemes for ground-breaking research?}

A comparison of the nine programs reveals further differences. Table 2 provides comprehensive data on total annual and relative funding levels and also on average funding duration. To begin with, schemes in the first program category have an average duration of roughly five years, whereas funds in the second program category are available, on average, for twoand-a-half years. Larger annual funding budgets reflect the longer duration of programs supporting individual scientists, as is the case for HIP, EURYI, and IRG (Table 2, row 6). By far the least-endowed programs, measured as the average amount spent per individual or project, are WCA and FIRST (Table 2, row 3).

While average funding duration allows an initial assessment of whether or not programs operate with a long-term perspective, the opportunity for grant renewal is also an important indicator. The funding schemes of KFP, EURYI, and IRG are clearly transitory: their support is provided to junior group leaders for a fixed period of up to five years without an option for renewal. In the KFP program, for example, group leaders are expected to be promoted to full professor status within the funding period or shortly thereafter. The Krupp Award can be understood as a signal to public research institutions, particularly universities, that its awardees merit full professorial status and research equipment levels. ${ }^{9}$ In the case of IRG and EURYI, scientists may apply for advanced investigator grants (a new EU-level funding program under preparation) but not again for IRG. ${ }^{10}$ Similarly, scientists with current grant support from the McDonnell Foundation are not eligible to apply for continued support of ongoing research. ${ }^{11}$ The same condition applies to VOBT, IDF, and FIRST, which provide project support for one period, typically between two and three years.

In contrast, WCA allowed grant renewals. A review of all projects funded under WCA shows that a considerable share of applicants availed themselves of this option and successfully applied for continued funding. Our interviewee from the Wellcome Trust stated that several grant renewals were the result of the generally low funding level at the beginning of WCA. Renewals allowed the purchase of instrumentation and consumables, an option that was not incorporated into the first round of WCA grants. The responsible unit at the Wellcome Trust not only upgraded those groups that were initially successful but also provided this opportunity to investigators who applied in the following years (Interview 3). Therefore, in the period 1996-2003, the average project funding nearly tripled from about $\$ 75,000$ to $\$ 205,000$, and the average project duration doubled, indicating an improved endowment of individual projects.

Grant renewal is also an important feature of HIP. Howard Hughes investigators can receive renewed funding for five additional years after an evaluation of the first period. The strength of HIP lies in its ability to fund long-term research and to explore research questions that are difficult to address in two- or three-year projects (Interview 4). One inter-

Table 2. Funding duration and budget measures

\begin{tabular}{|c|c|c|c|c|c|c|c|c|c|}
\hline & HIP & EURYI & KFP & IRG & MSI & VOBT & FIRST & IDF & WCA \\
\hline Average duration of funding in years & 5 & 5 & 5 & up to 5 & 3.7 & 3.2 & $2.8^{1}$ & 2.5 & 1.5 \\
\hline Grant renewal option & Yes & No & No & No & No & No & No & No & Yes \\
\hline $\begin{array}{l}\text { Average amount spent per individual } \\
\text { or project }\end{array}$ & $7.50 \mathrm{M}$ & $1.21 \mathrm{M}$ & $0.73 \mathrm{M}$ & $\begin{array}{l}1.33 \mathrm{M} \\
(\mathrm{BP})\end{array}$ & $0.38 \mathrm{M}$ & $0.45 \mathrm{M}$ & $58,000^{1}$ & $0.44 \mathrm{M}$ & $0.13 \mathrm{M}$ \\
\hline $\begin{array}{l}\text { Average amount spent per individual } \\
\text { or project per year }\end{array}$ & $1.5 \mathrm{M}$ & $0.24 \mathrm{M}$ & $0.15 \mathrm{M}$ & $\begin{array}{l}0.27 \mathrm{M} \\
(\mathrm{BP})\end{array}$ & $0.10 \mathrm{M}$ & $0.14 \mathrm{M}$ & $20,000^{1}$ & $0.18 \mathrm{M}$ & 85,000 \\
\hline $\begin{array}{l}\text { Funding range per individual or } \\
\text { project }\end{array}$ & n.a. & $\begin{array}{l}0.25-2.97 \\
M\end{array}$ & n.a. & $\begin{array}{l}0.43-2.14 \\
M(B P)\end{array}$ & $\begin{array}{l}30,000 \text { to } \\
0.48 \mathrm{M}\end{array}$ & $\begin{array}{l}53,800 \text { to } \\
1.48 \mathrm{M}\end{array}$ & $\begin{array}{l}14,500 \text { to } \\
0.27 \mathrm{M}\end{array}$ & $\begin{array}{l}46,900 \text { to } \\
1.63 \mathrm{M}\end{array}$ & $\begin{array}{l}2,500 \text { to } \\
0.29 \mathrm{M}\end{array}$ \\
\hline Average annual program spend & $450 \mathrm{M}$ & $39.50 \mathrm{M}$ & $0.96 \mathrm{M}$ & $\begin{array}{l}374 \mathrm{M} \\
(\mathrm{BP})\end{array}$ & $6.80 \mathrm{M}$ & $2.88 \mathrm{M}$ & $0.85 \mathrm{M}$ & $7.86 \mathrm{M}$ & $3.44 \mathrm{M}$ \\
\hline $\begin{array}{l}\text { Share of annual spend relative to } \\
\text { total annual research funding of } \\
\text { organization }\end{array}$ & $67 \%$ & n.a. & $20 \%$ & n.a. & $38 \%$ & $2.87 \%$ & $1.41 \%$ & $0.36 \%$ & $0.62 \%$ \\
\hline
\end{tabular}

Notes: $\quad$ All numbers are real budget numbers covering the period between start and end years (see Table 1), except for budget plan (BP) numbers

1. Refers to FIRST individual and institutional grants. Amounts were standardized to $\$$ US using a dollar-euro ratio of 0.9365 and a dollar-pound sterling ratio of 0.6104 (calculated mean for 1999-2006) 
viewee outside the Howard Hughes Medical Institute argued that if scientists were generally forced to carry out only short-term research projects or clusters of such projects, the requirement would bias the system towards certain kinds of research and certain kinds of questions: 'And I think that is why Howard Hughes is so valued to certain investigators because it provides them with long-term support' (Interview 7). However, although several HIP investigators are funded for two periods, only a few receive renewals more than twice (Interview 4).

Another conspicuous finding is that programs in the first category (supporting individuals and careers) typically represent a substantial share of the funding agency's research spending, in the range $20-67 \%$. In contrast, programs in the second category (supporting projects) are comparatively small relative to other funding schemes within the same organization. In these initiatives, the share was 0.38$2.87 \%$ (Table 2, row 7). This difference indicates a major gap in the institutional weight these programs carry. While programs such as HIP, MSI, or IRG are hosted by institutions that are more or less entirely engaged in their particular missions to fund highly creative research, the same cannot be said for programs such as VOBT, FIRST, WCA, or IDF. For example, MSI dedicates greater than a hundred times more of its budget, in relative terms, to a dedicated program of funding creative science than does IDF (38\% vs $0.36 \%$ ). Programs from agencies with such a dedicated mission also develop considerable reputations over time, which helps their grant holders compete successfully in other funding streams. For instance, several interviewees compared the reputation of HIP with that of institutes of the Max Planck Society, a leading institution for fundamental, multidisciplinary research in Germany (Interviews $4,7,8$ ).

In summary, average funding duration, grant renewal option, and share of a funding agency's program spending relative to its total research sponsorship are three complementary indicators that discriminate between the nine programs under review. While the first and the third indicators confirm our initial two program categories, the second indicator reveals that there are also cross-category similarities, for instance between WCA and HIP. As we show below, the nine schemes are even more similar in terms of the procedures used to recruit scientists or select projects.

\section{Which procedures and criteria are used to select scientists for funding programs for ground-breaking research?}

The nine funding schemes employ similar processes of selecting applications. This similarity applies not only in the selection components (self-nomination, application by institution, open competition, internal pre-review by administrative officers, and peer review by advisory panels or external scientists) but also in the various combinations of these components. In contrast, there are noteworthy differences between the schemes with respect to the criteria they use to recruit scientists or select projects. The similarities and differences are sketched below.

Nominations Several programs, particularly in the first category (supporting individuals and careers), have traditionally admitted only applications submitted by institutions on behalf of the scientist or group leader. For example, KFP does not accept selfnominations to the Krupp Foundation; candidates must be nominated either by other individuals or by research organizations. Until 2002, HIP also asked the home institutions of candidates to select candidates and submit applications to the Howard Hughes Medical Institute. Generally, however, selfnominations are becoming more common. A case in point is HIP. Since the early 1990s, the Hughes Institute has solicited nominations from more than 200 distinguished universities and academic health centers around the USA to identify researchers with the potential to make significant contributions to science. The Hughes Institute invited these institutions to nominate two to four of their most innovative researchers, focusing on those who were rising in their careers. In their currently ongoing nomination process, however, the Hughes Institute invites faculty members to submit their names for consideration. This is perceived within the Hughes Foundation as a 'major change' from a highly selective to an open application process (Interview 8).

In the case of the MSI program, the McDonnell Foundation initially considered operating with a selection process like that of the McArthur Fellow Program, in which a distinguished panel of highly recognized individuals nominates candidates without a competitive application process. ${ }^{12}$ However, the McDonnell Foundation decided to let scientists apply through their institutions. In principle, this process ensures that novel ideas from researchers working at lesser known institutions have a fair chance for entering (and succeeding) in the application process. Although we do not evaluate here whether or not this principle was consistently applied in the MSI program, the feedback from a representative of the McDonnell Foundation suggests that it was applied successfully in practice: 'And in several of those fields that we have funded, (...) people who we funded would not have gotten funded if we had used this other mechanism. Because they were not at the leading institutions. (...) So to a certain extent, we did not want to eliminate these people from applying' (Interview 7). ${ }^{13}$

Internal and external reviews Nearly all funding schemes combine an internal pre-selection phase, overseen by science administrators, and in-depth reviews by either external peer scientists or an internal scientific review board. Programs in the first category tend to delegate the selection process to 
their internal scientific advisory boards, which have renowned scholars as members. External reviews are requested in these schemes only when there is insufficient expertise represented on the advisory panels. Because HIP and MSI provide support mainly in the biomedical sciences, they each have one major advisory panel whose members are published on the program websites. ${ }^{14}$ In the case of IRG, which allocates funding to all scientific areas, more than 20 such advisory bodies, each spanning several research fields, are responsible for proposal selection. In the second program category, however, involvement of external peer-review is commonplace.

Several programs run selection processes similar to those of mainstream programs. For instance, VOBT uses application procedures identical to those of their other programs. Our interviewee from the Volkswagen Foundation stated that the foundation uses the normal selection routine because it endows 'wild ideas' with legitimacy: 'We need a basis for making a recommendation to our board of governors to fund a project anywhere between $\$ 100,000$ or $\$ 300,000$. There is no difference to the other programs we run' (Interview 6). In contrast, other programs have opted to apply particularly tailored peer-review processes. In the EURYI selection process, for instance, two expert panels review transdisciplinary proposals (those that go beyond one particular research field or discipline). Although evaluation by two panels is meant to give transdisciplinary applications fairer treatment, Langfeldt and Brofoss (2005) report that double evaluation may, in fact, be disadvantageous to the applicants involved because the success rates of transdisciplinary proposals are much lower than those of their competitors (Langfeldt and Brofoss, 2005: 43). Thus, in spite of good intentions, double evaluation may inadvertently be counterproductive, with the greater number of reviews increasing the probability that doubts will be raised about a project's feasibility and subsequently decreasing the probability that it will succeed in the final selection round.

Apart from unintended negative consequences, specifically tailored peer-review routines that include

\section{In spite of good intentions, double evaluation may inadvertently be counterproductive, with the greater number of reviews increasing the probability that doubts will be raised about a project's feasibility and subsequently decreasing the probability that it will succeed in the final selection round}

heightened evaluation requirements seem problematic because they tend to increase administrative costs both for the applicants and for the funding agency. However, a higher level of administrative effort might not only discourage potential applicants from submitting their proposals but also may eventually lead to the termination of the scheme. Our interviewee from the Wellcome Trust confirmed that one of the reasons for discontinuing WCA was its relatively high level of administration, which was considered an ineffective way of spending research money (Interview 3).

Also, in light of the well-known biases in peerreview processes, it is compelling that only one program explicitly departs from the peer-review model, whereas all other programs strongly rely on it. IDF arranges a so-called 'sandpit selection process', a decision-making process involving 20-30 participants and based on intensive discussions during a five-day residential, interactive workshop. The IDF website states: 'An essential element of a sandpit is a highly multidisciplinary mix of participants taking part, some being active researchers and some being potential users of research outcomes, to drive lateral thinking and radical approaches to addressing particular research challenges'. ${ }^{15}$ IDF has only operated since 2005, so it is certainly too soon to judge the appropriateness of this new tool as an effective means of selecting transdisciplinary projects. However, a short selection of the IDF project titles clearly shows that it strives to fund unorthodox and unconventional research: 'Coping with extreme weather events', 'Taking care of the patient: new thinking in mobile healthcare delivery', and 'Computing with uncertain future devices'. ${ }^{16}$

Despite the strong peer-review component in almost all programs, another consideration is the efforts these programs make to ensure that unorthodox and creative applications have a chance of entering into funding. For instance, FIRST is governed by a scientific board with members representing a broad range of different research disciplines and institutes. To guarantee impartiality, the term of board members is limited to three years. In the case of WCA, the Wellcome Trust conducted an ex-post evaluation to determine whether the peer-review process worked properly. Using a masked randomized experiment, the evaluation team confirmed that WCA projects, in comparison to a sample of standard project grants, were perceived ex-post as much more risky, novel, speculative, adventurous, and innovative (Grant and Allen, 1999).

Selection criteria In a comparison of the criteria programs used for selecting individuals or projects, interesting patterns emerge (Table 3 ). First, none of the first category programs mentions riskiness or speculativeness as decisive selection criteria, whereas all second category programs regard this dimension as important or indispensable. This distinction does not mean that successful candidates in 


\begin{tabular}{lccccccccc}
\hline & HIP & KFP & MSI & EURYI & IRG & WCA & VOBT & IDF & FIRST \\
Originality of proposal/candidate potential & ++ & ++ & ++ & ++ & ++ & ++ & ++ & ++ & ++ \\
Speculative nature/riskiness of proposal or project & $\circ$ & $\circ$ & $\circ$ & $\circ$ & $\circ$ & ++ & + & + & ++ \\
Quality of previous research/track record of proposer & ++ & ++ & ++ & ++ & ++ & + & + & - & + \\
Potential payback to society & + & - & + & $\circ$ & $\circ$ & ++ & - & ++ & - \\
Multidisciplinarity of research & ++ & $\circ$ & + & - & + & + & + & ++ & ++ \\
Group leadership qualification & ++ & ++ & + & ++ & ++ & 0 & 0 & 0 & 0 \\
\hline
\end{tabular}

Notes: $\quad$ ++ indispensable; + important; - not important; o not explicitly stated

Assessments are derived both from questionnaire and interview responses (see Appendixes 1 and 2 ), and a critical review of existing documents, brochures and websites by the author

first category programs do not undertake risky or ambitious research. However, scientists applying to these schemes are not selected with respect to the riskiness of a particular project, but rather according to their scientific promise, their track records, and their leadership qualifications. These qualities are regarded as prerequisites for undertaking groundbreaking research. Although these three criteria are indispensable or important in the first category programs, they are not so necessary in all second category programs (Table 3 ).

The latter programs tend instead to prioritize multidisciplinarity as a selection criterion. This approach is complementary to what one would expect from discipline-specific research councils and therefore the second category programs occupy a funding niche that regular funding initiatives leave empty. An interesting difference also exists within the second category programs. While FIRST and VOBT fund basic research projects, WCA and IDF are more focused on real-world problems, and they ask applicants to address perceived societal needs. The applied, problem-oriented approach is particularly evident in the IDF initiative.

\section{CONCLUSIONS}

This paper began with the observation that a major challenge for research management and science policy is to support scientists in exploring new research frontiers. But because experimentation with new alternatives offers returns that are uncertain, distant, and often negative, exploration of new research paths is often discouraged, while the often positive, proximate, and predictable returns on the refinement and extension of existing competences, technologies, and paradigms encourage the exploitation of existing research paths.

Our comparison of selected funding initiatives for high-risk and ground-breaking research shows that several of these programs strive to remedy specific deficiencies in national research systems with respect to the exploration mode in science, such as the lack of core funding for university professors in the United
States, or the persistent asymmetry in the institutional support that junior and senior professors receive in Germany. We also find two broad categories among the nine programs. Programs in the first category provide individual scientists with the means to engage in the long-term development of bold and sometimes risky ideas that might be too multidisciplinary or too unorthodox for research councils. These programs rest on the conviction that outstanding individuals are the key drivers in the advancement of science. In contrast, programs in the second category target unconventional ideas that would probably be rejected under peer review but that can at the same time be packaged into the format of a research project. Such programs are perhaps best regarded as support vehicles for unconventional ideas that are developed until they are better prepared for more traditional follow-up funding elsewhere.

Despite considerable variation within these two broad classes of programs, the two categories have conspicuous differences. Schemes in the first category have an average duration of roughly five years and thereby run twice as long as their counterparts in the second category. Their long-term perspective is also reflected in larger annual funding budgets. In addition, while programs in the first category represent a substantial share of the funding agency's research spending, programs in the second category are comparatively small relative to other funding schemes sponsored by the same organization. This difference indicates a major gap in the institutional weight these programs carry. Programs from agencies with a dedicated mission to fund groundbreaking research have developed reputations over time, which helps their grant holders compete successfully in other funding streams.

From a science policy perspective, it is important to discuss the strengths and the weaknesses of existing funding programs for ground-breaking research (fourth question stated in the introduction). In particular, shortcomings and problems associated with some of the schemes deserve a critical appraisal. The following discussion is meant to reflect on the possible effects certain structural and operational features have on a program's effectiveness in 
supporting explorative research. Consequently, we invite science policy makers to reconsider the design of established schemes and to engage in a debate about how future initiatives for ground-breaking research should be organized.

To begin with, several schemes impose arbitrary funding thresholds. Such thresholds are problematic because they prevent sponsors from fully using the pool of creative applicants or proposals. This situation is evident in the cases of KFP and EURYI. While HIP and MSI do not impose a threshold on the number of applicants that can be funded in each funding round, KFP and EURYI do. In the case of the Krupp Foundation, on average, one junior professor is funded every year; in the case of EURYI, 25 junior scientists received the award per year. In light of the findings of Melin and Danell (2006), the number of qualified junior professors in Germany and junior scientists in the European Union is presumably much higher than the number of annual awards that these two programs provide. An evaluation of EURYI reported 778 applicants in the first year of the program, indicating an extremely low proposal success rate of $3.2 \%$. That fact may have deterred potential applicants from submitting proposals in the second year, when the number of applicants dropped to 662 (Langfeldt and Brofoss, 2005: 16). Hence, a better practice might be to locate the break-even point between applications and funded projects in each application round rather than to set arbitrary a priori thresholds.

Another shortcoming is that none of the schemes take into account each applicant's level of core funding or the number of their ongoing research projects. Several studies in the sociology of science, however, have shown that small research groups are often more productive than larger ones (Tunzelmann et al., 2003). Small group size is also a distinctive feature of groups with a record of highly creative research (Heinze et al., 2008). Small group size is also a distinctive feature of groups with a record of highly creative research. Therefore, additional resources may not necessarily induce unconventional and creative research if the groups are too large or group members are already fully committed to ongoing research projects. Without taking such factors into consideration, several programs might end up sponsoring groups that absorb resources without much effect. Hence, funding agencies should consider better aligning their resources with the existing funding of successful applicants.

\section{Small group size is also a distinctive feature of groups with a record of highly creative research}

Third, most of the programs analyzed here dispose of relatively small budgets only. Thus, one might question whether $0.36 \%$ (IDF) or $0.62 \%$ (WCA) of a funding agency's total budget really makes a difference. This question could possibly be answered if the ratio of ground-breaking research to 'normal science' were known. However, this ratio is unknown, and it would be presumptuous to estimate it without proper data. Therefore, rather than arguing that programs should reserve a certain share of their budget, say at least $10 \%$, for multidisciplinary and high-risk research, there is a more fundamental issue: Should funding programs for ground-breaking research be set up within existing funding organizations, or should new funding agencies be set up with a dedicated mission to sponsor ground-breaking research? There are reasons to believe that the latter option is preferable.

Our analysis suggests that if programs for groundbreaking research are established within an existing funding agency, they tend to be either a residual funding category (e.g. VOBT) or a signal to the outside world of the agency's commitment to groundbreaking research (e.g. FIRST, WCA, IDF, EURYI). In both cases, however, programs challenge already existing funding schemes within the agency because the label 'high-risk' or 'creative' carries the inference that all other schemes support non-'high-risk' or non-'creative' research. Therefore, such schemes might internally be perceived as a threat to established wisdom about how good research proposals should look and how applications should be processed. Consequently, to increase a newcomer's intra-agency legitimacy, such schemes either become part of the regular bureaucratic selection processes that apply to all other schemes (e.g. VOBT, partly WCA), or applications are put under special scrutiny and evaluation routines (e.g. FIRST, WCA, EURYI).

However, as the analysis of EURYI and WCA has shown, special evaluation may inadvertently turn out to be counterproductive to the program's mission (EURYI), and heightened evaluation requirements might increase administrative costs above an acceptable level, so that programs are terminated altogether (WCA). In contrast, if programs are more or less identical with the organizations that operate them, these problems are not observed. Rather, programs such as HIP, MSI, or KFP have developed reputations within the scientific communities that confer on them considerable legitimacy. Therefore, science policy makers should reconsider the 'easy option' of adding just another funding line to their agency's portfolio. Rather, they might be better advised to set up a new agency with a dedicated mission for such funding. While new agencies certainly require substantial resources, our discussion demonstrates that such investments are likely to strengthen the forces of exploration.

Finally, except for one program, all schemes operate with the peer-review model, either in the 
format of scientific advisory bodies or with external reviewers. Our interviews with representatives from funding agencies suggest that while they are well aware of the conservative bias of the peer-review mechanism, they still search for unanimous judgment. This approach means that when one reviewer gives a proposal a high rating and another reviewer rates it very low, agencies tend to discard the proposal. None of the interviewees, however, mentioned using controversy over applications in the decision-making process as a signal that a proposal, by triggering such debate, was perhaps particularly worth funding. Given the fact that the nine programs under review aim at funding 'high-risk' research questions, it is compelling that the decision process itself tends to be rather risk averse. Interviewees, including those from private foundations, typically argued that they want to make an investment that bears fruit; that their budget is relatively small; and that their decisions must be fully accountable. Thus, even in programs for high-risk research, the 'forces of exploitation’ (March, 1991) remain strong.

\section{Appendix 1. Questionnaire for program survey (extract)}

Does your organization have dedicated program(s) to fund highly innovative research?

$$
\text { Yes No }
$$

Please give details on the program. If there is more than one program, please copy and complete this questionnaire as many times as is necessary.

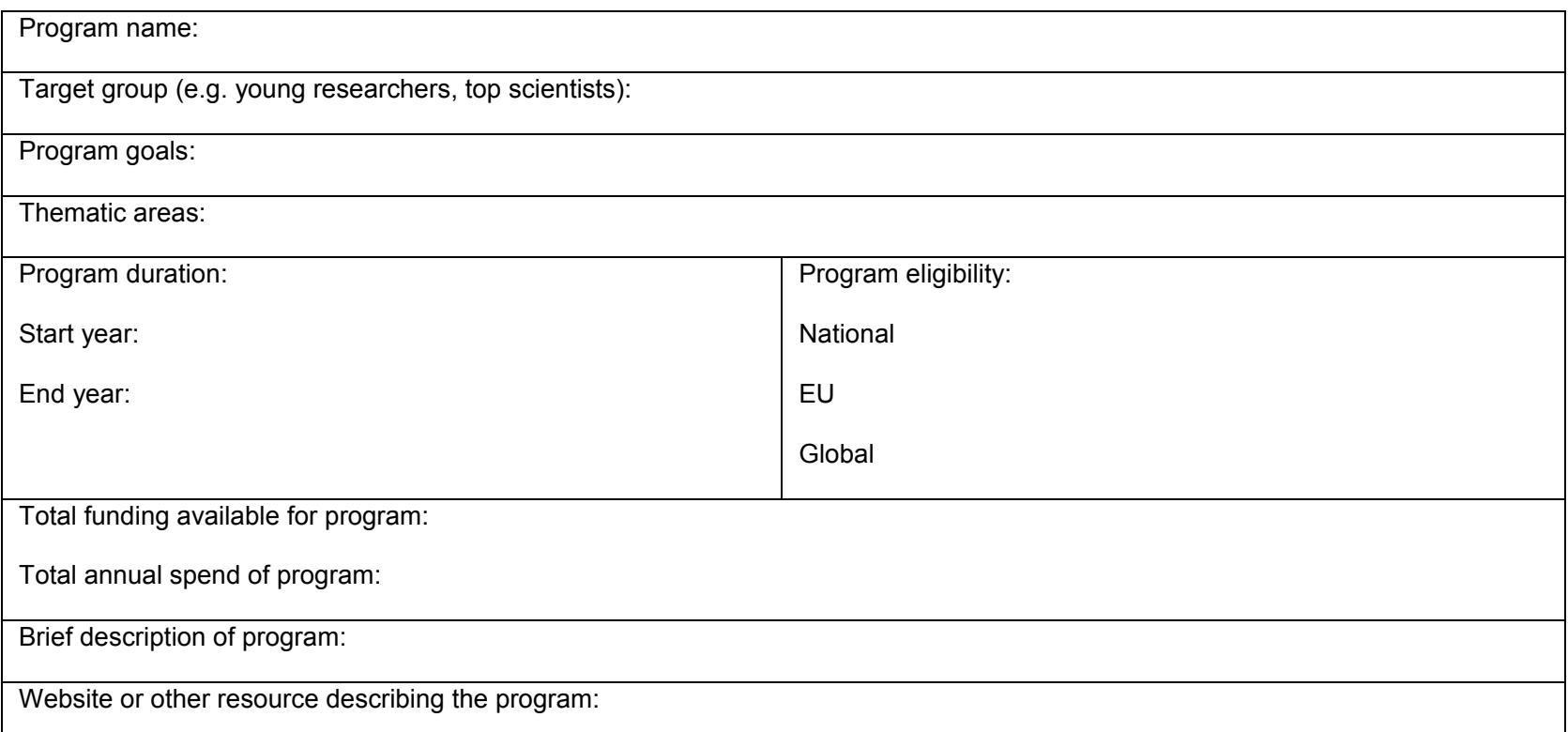

Please indicate which criteria are important for allocating funds in the program. We suggest an initial set, but please add any further criteria you consider relevant.

Indispensable Important Not Important

- $\quad$ Originality of proposal

- Speculative nature of project

- $\quad$ Potential payback to society

- Collaboration with other institutions

- $\quad$ Addressing perceived need of society

- $\quad$ Track record of proposer

- Multidisciplinarity of research:

- $\quad$ Other (specify): 


\section{Appendix 2. List of interviews}

The interviews were conducted with two groups of individuals. First, in the context of the study on institutional conditions for research creativity (Heinze et al., 2007a,b; 2008), the author interviewed recipients of funding schemes $(1,2,4,8)$. Second, leading officials of funding agencies were interviewed to obtain more in-depth knowledge about their work, the selection process and the selection criteria $(3,5,6,7)$. Since anonymity was guaranteed to all interviewees, their names or positions are not disclosed. All interviews were recorded and fully transcribed (except for interviews 5 and 8 ).

\begin{tabular}{lllll}
\hline & Affilation of Interviewee & Country & Interview date & Interview type \\
1 & University of Heidelberg & Germany & 6 Feb 2006 & In person \\
2 & Max-Planck-Institute & Germany & 27 Feb 2006 & In person \\
3 & Wellcome Trust & UK & 2 May 2006 & Telephone \\
4 & Harvard University & USA & 6 May 2006 & In person \\
5 & Israel Science Foundation & Israel & 20 May 2006 & In person \\
6 & Volkswagen Foundation & Germany & 14 Nov 2006 & Telephone \\
7 & James McDonnell Foundation & USA & 20 Nov 2006 & Telephone \\
8 & Howard Hughes Foundation & USA & 8 Jan 2007 & Telephone \\
9 & Max-Planck-Institute & Germany & 10 Jul 2007 & In person \\
\hline
\end{tabular}

\section{Notes}

1. Another major trend, which is not discussed here, is the increasing bureaucratization of university research (cf. Gornitzka et al., 1998).

2. The survey was conducted by Professor Patrick Prendergast and Sheena Brown (Trinity College Dublin). The author is grateful for their help and advice.

3. It should be noted that the selection of these schemes is not representative of all existing programs. There are several other prestigious multi-year schemes for individual scientists that award substantial sums of research money, such as the Leibniz Prize in Germany (\$US2.67 M), the Spinoza Award in the Netherlands (\$US1.6 M), the Descartes Prize of the European Commission ( $\$$ US1.23 M), or the NIH Director's Pioneer Award in the United States (\$US1.0 M). Likewise, although only a few dedicated institutional or project funding programs seem to exist within established research councils or foundations, we do not cover all existing initiatives. It should be noted that the cash value of the Leibniz, Spinoza and Descartes prizes were calculated using a dollar-euro ratio of 0.9365 (mean for 1999-2006).

4. Available at <http://www.hhmi.org/research/investigators/ investigator_faq.html>, last accessed 8 May 2008.

5 Available at <http://www.hhmi.org/research/investigators/ investigator faq.html>, last accessed 8 May 2008

6. Available at <http://www.jsmf.org/apply/research/index.htm>, last accessed 8 May 2008

7. The author is grateful to Professor Eli Pollak (Weizman Institute, Israel) for providing details on this project.

8. See <http://www.mpg.de/english/aboutTheSociety/mission Statement/excellencePrinciple/harnackPrinciple/index. html>, last accessed 8 May 2008. See also Vierhaus (1992) and Heinze and Arnold (2008).

9. Available at <http://www.krupp-stiftung.de/>, last accessed 8 May 2008.

10. Available at <http://erc.europa.eu>, last accessed 8 May 2008.

11. Available at <http://www.jsmf.org/apply/research/eligibility. htm>, last accessed 8 May 2008.

12. Available at <http://www.macfound.org/site/c.IkLXJ8MQKrH/ b.959463/k.9D7D/Fellows Program.htm>, last accessed 8 May 2008.

13. In the case of MSI, self-applications are not processed for legal reasons. In the USA, private foundations are only permitted to fund organizations with non-profit status.

14. Available at <http://www.hhmi.org/about/srb.html>, last accessed 8 May 2008; available at <http://www.jsmf.org/ programs/bmb/panel.htm>, last accessed 8 May 2008; available at <http://www.jsmf.org/programs/cs/panel.htm>, last accessed 8 May 2008; available at <http://www. jsmf.org/programs/bc/panel.htm>, last accessed 8 May 2008.

15. Available at <http://www.epsrc.ac.uk/ResearchFunding/ Opportunities/Networking/IDEASFactory/default.htm>, last accessed 8 May 2008.

16. Available at <http://www.epsrc.ac.uk/ResearchFunding/ Programs/Cross-EPSRCActivities/IDEASFactory/default. htm>, last accessed 8 May 2008.

\section{References}

Akerlof, G A 1994. In: Swedberg R ed. Economics and Sociology. Redefining their Boundaries: Conversations with Economists and Sociologists, pp. 61-77. Princeton, New Jersey: Princeton University Press.

Berezin, A 1998. The perils of centralized research funding system. Knowledge, Technology and Policy, 11(3), 5-26.

Bourke, $P$ and $L$ Butler 1999. The efficacy of different modes of funding research: perspectives from Australian data on the biological sciences. Research Policy, 28, 489-499.

Chubin D E and E J Hackett 1990. Peerless Science: Peer Review and U.S. Science Policy. Albany, New York: State University of New York Press.

Crow, M and B Bozeman 1998. Limited by Design. R\&D Laboratories in the U.S. National Innovation System. New York: Columbia University Press.

Gornitzka, A, S Kyvik, I Marheim Larsen 1998. Bureaucratisation of universities. Minerva, 36(1), 21-47.

Grant, J and J Allen 1999. Evaluating high risk research: an assessment of the Wellcome Trust's Sir Henry Wellcome Commemorative Awards for Innovative Research. Research Evaluation, 8 (3), 201-204.

Heinze, T and N Arnold 2008. Die Governancestrukturen des außeruniversitären, öffentlich finanzierten Forschungssektors in Deutschland. Manuscript, Karlsruhe.

Heinze, T, P Shapira, J Senker, S Kuhlmann 2007a. Identifying creative research accomplishments: methodology and results for nanotechnology and human genetics. Scientometrics, 70, 125-152.

Heinze, T, P Shapira, J Rogers, J Senker 2007b. Creativity capabilities and promotion of highly innovative research in Europe and the United Sates. Final report, Karlsruhe. 
Heinze, T, P Shapira, J Rogers, J Senker 2008. Research creativity. An exploration of pathbreaking science. Research Policy (forthcoming).

HLEG (High-Level Expert Group on Frontier Research) 2005. Frontier research: The European Challenge. Luxembourg: Office for Official Publications of the European Communities.

Horrobin, D F 1996. Peer review of grant applications: a harbinger for mediocrity in clinical research? Lancet, 348(9037), 1293-1295.

Hughes Medical Institute ed. 2005. Serving science. Annual Report 2005. Chevy Chase, Maryland, USA: Hughes Medical Institute.

Hughes Medical Institute ed. 2004. Innovations in biomedicine. Annual Report 2004. Chevy Chase, Maryland, USA: Hughes Medical Institute.

Jansen, D ed. 2007. New Forms of Governance in Research Organizations. From Disciplinary Theories Towards Interfaces and Integration. Dordrecht, The Netherlands: Kluwer.

Krupp-Stiftung ed. 2004. Alfried Krupp-Förderpreis für junge Hochschullehrer. Die 25 Preisträger 1986 bis 2004. Essen, Germany: Krupp-Stiftung.

Langfeldt, L and K E Brofoss 2005. Evaluation of the European young investigator awards scheme. Working paper, October 2005. Oslo, Norway: NIFU STEP.

Langfeldt, $L$ 2001. The decision-making constraints and processes of grant peer review, and their effects on the review outcome. Social Studies of Science, 31(6), 820-841.

Laredo, P and P Mustar eds. 2001. Research and Innovation
Policies in the new Global Economy. Cheltenham, UK: Edward Elgar.

Laudel, G 2006. The art of getting funded: how scientists adapt to their funding conditions. Science and Public Policy, 33(7), 489-504.

March, J G 1991. Exploration and exploitation in organizational learning. Organization Science, 2, 71-87.

Melin, G and R Danell 2006. The top eight percent: development of approved and rejected applicants for a prestigious grant in Sweden. Science and Public Policy, 33(10), 702-712.

Polanyi, M 1966. The Tacit Dimension. London: Routledge \& Kegan Paul.

Polanyi, M 1969. Knowing and Being, with an introduction by M Grene. Chicago, Illinois, USA: Chicago University Press.

Shapira, P and S Kuhlmann eds. 2003. Learning from Science and Technology Policy Evaluation. Cheltenham, UK: Edward Elgar.

Travis, G D L and H M Collins 1991. New light on old boys: cognitive and institutional particularism in the peer review system. Science, Technology and Human Values, 16(3), 322-341.

Tunzelmann, N v, M Ranga, B Martin and A Geuna 2003. The Effects of Size on Research Performance: A SPRU Review. Brighton, UK: University of Sussex.

Vierhaus, R 1992. Bemerkungen zum sogenannten HarnackPrinzip. Mythos und Realität. In: Mayer K U (ed.) Generationsdynamik in der Forschung, pp. 168-180. Frankfurt: Campus. 